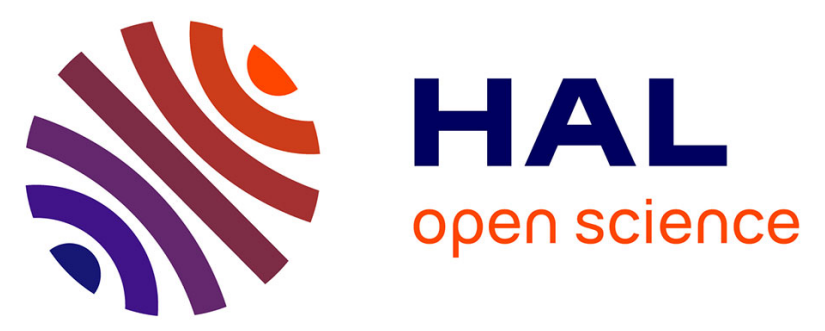

\title{
Level of viral suppression and the cascade of HIV care in a South-African semi-urban setting in 2012
}

Kévin Jean, Adrian Puren, Ewalde Cutler, Beverley Singh, Julie Bouscaillou, Reathe Rain-Taljaard, Dirk Taljaard, Eleanor Gouws, Pascale Lissouba, David Lewis, et al.

\section{To cite this version:}

Kévin Jean, Adrian Puren, Ewalde Cutler, Beverley Singh, Julie Bouscaillou, et al.. Level of viral suppression and the cascade of HIV care in a South-African semi-urban setting in 2012. AIDS. Official journal of the international AIDS Society, 2016, 30 (13), pp.2107-2116. 10.1097/QAD.0000000000001155 . hal-01350981

\section{HAL Id: hal-01350981 https://hal.science/hal-01350981}

Submitted on 3 Aug 2016

HAL is a multi-disciplinary open access archive for the deposit and dissemination of scientific research documents, whether they are published or not. The documents may come from teaching and research institutions in France or abroad, or from public or private research centers.
L'archive ouverte pluridisciplinaire HAL, est destinée au dépôt et à la diffusion de documents scientifiques de niveau recherche, publiés ou non, émanant des établissements d'enseignement et de recherche français ou étrangers, des laboratoires publics ou privés. 
QAD

DOI: $10.1097 / Q A D .0000000000001155$

Title (84 characters)

Level of viral suppression and the cascade of HIV care in a South-African semi-urban setting in 2012

\section{Short title: Cascade of HIV care in South Africa}

Kévin JEAN ${ }^{1,2}$, Adrian PUREN ${ }^{3,4}$, Ewalde CUTLER ${ }^{3}$, Beverley SINGH ${ }^{3}$, Julie BOUSCAILlOU ${ }^{5}$, Reathe RAIN-TALJAARD ${ }^{6}$, Dirk TALJAARD ${ }^{7}$, Eleanor GOUWS ${ }^{8}$, Pascale LISSOUBA ${ }^{9}$, David A. LEWIS ${ }^{10,11}$, Gilles PEYTAVIN ${ }^{12}$, Bertran AUVERT ${ }^{2,13,14^{*}}$.

${ }^{1}$ MRC Centre for Outbreak Analysis, Department of Infectious Disease Epidemiology, Imperial College, London, United Kingdom

2 INSERM U1018, 94800 Villejuif, France

${ }^{3}$ HIV department, National Institute for Communicable Diseases, National Health Laboratory Service, Johannesburg, South Africa

${ }^{4}$ University of the Witwatersrand, Faculty of Health Sciences, Johannesburg, South Africa

${ }^{5}$ Médecins du monde, Paris, France

${ }^{6}$ Progressus Research and Development, Johannesburg, South Africa

${ }^{7}$ CHAPS, Parktown, Johannesburg, South Africa

${ }^{8}$ UNAIDS, Geneva, Switzerland

${ }^{9}$ Medecins sans frontières, Paris, France

${ }^{10}$ Western Sydney Sexual Health Centre, Sydney, Australia

${ }^{11}$ University of Sydney, Sydney, Australia

Copyright ( 2016 Wolters Kluwer Health, Inc. Unauthorized reproduction of this article is prohibited. 
${ }^{12}$ Pharmacology, APHP- Bichat-Claude Bernard, Paris, France

${ }^{13}$ Assistance Publique-Hôpitaux de Paris, Hôpital Ambroise Paré, Boulogne-Billancourt, France

${ }^{14}$ Faculty of Medicine, University of Versailles-Saint Quentin, Versailles, France

* Corresponding author

Correspondance to:

Bertran AUVERT

INSERM U1018, 16 avenue Paul Vaillant-Couturier, 94807 Villejuif France bertran.auvert@uvsq.fr

$\begin{array}{ll}\text { Kévin Jean } & \text { k.jean@imperial.ac.uk } \\ \text { Adrian Puren } & \text { adrianp@nicd.ac.za } \\ \text { Ewaldé cutler } & \text { ewaldec@ nicd.ac.za } \\ \text { beverley Sing } & \text { beverleys@nicd.ac.za> } \\ \text { Julie Bouscaillou } & \text { julie.bouscaillou@gmail.com> } \\ \text { Reathe Rain-Taljaard } & \text { rain@progressus.co.za } \\ \text { Dirk Taljaard } & \text { dirk@chaps.org.za } \\ \text { Eleanor Gouws } & \text { gouwse@unaids.org } \\ \text { Pascale Lissouba } & \text { plissouba@aol.com } \\ \text { David Lewis } & \text { david.lewis2@sydney.edu.au } \\ \text { Gilles Peytavin } & \text { gilles.peytavin@bch.aphp.fr } \\ \text { Bertran Auvert } & \text { bertran.auvert@uvsq.fr }\end{array}$

Word count: 3465

Copyright @ 2016 Wolters Kluwer Health, Inc. Unauthorized reproduction of this article is prohibited. 


\section{Abstract (249 words)}

Objective: In 2012, seven years after the introduction of ART in the South-African township of Orange Farm, we measured the proportion of HIV-positive people who were virally suppressed, especially among high risk groups (women 18-29y and men 25-34y).

Design: A community-based cross-sectional representative survey was conducted among 3293 men and 3473 women.

Methods: Study procedures included a face-to-face interview and collection of blood samples that were tested for HIV, 11 antiretroviral drugs (ARVs) and HIV-Viral Load (VL).

Results: HIV prevalence was 17.0\%[95\%CI: 15.7-18.3\%] among men and 30.1\%[28.5$31.6 \%]$ among women. Overall, 59.1\%[57.4-60.8\%] of men and 79.5\%[78.2-80.9\%] of women had previously been tested for HIV. When controlling for age, circumcised men were more likely to have been tested compared to uncircumcised men $(66.1 \%$ vs $53.6 \%$; $\mathrm{p}<0.001)$. Among HIV+, 21.0\%[17.7-24.6\%] of men and 30.5\%[27.7-33.3\%] of women tested positive for on or more ARV. Using basic calculations we estimated that, between 2005 and 2012, ART programs prevented between $46 \%-63 \%$ of AIDS-related deaths in the community. Among ARV+, 91.9\%[88.7-94.3\%] had viral suppression (VL<400copies/mL). The proportion of viral suppression among HIV+ was 27.0\%[24.3-29.9\%] among women and $17.5 \%[14.4-20.9 \%]$ among men. These proportions were lower among the high risk groups: $15.6 \%[12.1-19.7 \%]$ among women and 8.4\%[5.0-13.1\%] among men. 
Conclusion: In Orange Farm, between 2005 and 2012, ART programs were sub-optimal and, among those living with HIV, the proportion with viral suppression was still low, especially among the young age groups. However, our study showed that in reality ARVs are highly effective in viral suppression at an individual level.

\section{Keywords}

Africa; HIV; ARV; Viral load; Male circumcision; HIV testing; Cascade of HIV care.

Copyright @ 2016 Wolters Kluwer Health, Inc. Unauthorized reproduction of this article is prohibited. 


\section{Introduction}

Antiretroviral treatment (ART) has been rapidly scaled-up in sub-Saharan Africa in the last decade. It was initially used to prevent HIV-related deaths, as well as for the prevention of mother-to-child transmission (PMTCT) [1,2]. More recently, different studies highlighted the preventive effect of ART on onward sexual transmission [3-5], which has led the World Health Organization (WHO) to recommend the use of ART for both individual and collective benefits [6]. However, in order to have an impact on HIV incidence at a population-level, the coverage of those receiving treatment and having a suppressed Viral Load (VL) (as a proportion of all people living with HIV) should be high [7,8]. Particularly, ART coverage and viral suppression should be high among the age groups representing the highest HIV incidence levels. Recently, the Joint United Nations Programme on HIV/AIDS (UNAIDS) proposed ambitious treatment targets for 2020, suggesting that $90 \%$ of all HIV-infected people should be diagnosed by 2020, $90 \%$ of all HIV-diagnosed people should be receiving sustained ART, and $90 \%$ of people receiving ART should be virally suppressed [9]. Meeting this "90-90-90" target would result in viral load suppression among $73 \%$ of all people living with HIV and would contribute significantly to the reduction of new infections and AIDSrelated deaths and the UNAIDS goal of ending the AIDS epidemic by 2030.

Information documented to date highlights many failures along the so-called cascade of HIV care, with suboptimal efficiency of HIV testing, linkage to HIV care, ART initiation and viral suppression [10-12]. Estimating the overall proportion of viral suppression and identifying failures along the cascade of care in specific settings is a starting point for strategically planning the way forward towards reaching the UNAIDS 2020 targets and for identifying ways to improve ART program efficiency. Moreover, the majority of the studies published to date are clinic based and thus did not provide insight into those not linked or retained in care [13]. 
Relying on a representative sample of the adult population from a South-African hyperendemic peri-urban setting where an intensified HIV prevention program has been conducted since 2008, our main objective was to estimate the proportion of HIV-infected adults with viral suppression, especially among the highly-exposed age groups. The secondary objectives were a) to document completion of each step of HIV cascade and to identify factors associated with their successful completion, and b) to assess the effectiveness of the ART program in preventing AIDS-related deaths between 2005 and 2012.

\section{Methods}

\section{Study community}

This study was conducted in the township of Orange Farm, located approximatively 40km from Johannesburg, South Africa. The adult population is estimated at around 110,000. The township is located in a district with one of the most severe HIV epidemics in the world, with HIV prevalence estimated at 30\% among women attending antenatal clinics in 2011 [14]. ART became available in 2004 in the community, but was only available throughout all Orange Farm's clinics in 2005. This later date was retained as the starting date of the ART program for the purpose of our study. Orange Farm was the setting of the first randomized controlled trial on voluntary male medical circumcision (VMMC), conducted between 2002 and 2004 [15], and of an intensified VMMC scale-up program conducted since 2008 [16]. This program includes community mobilization and free VMMC. In the clinics offering VMMC, free HIV counseling and testing (HCT) is also offered.

\section{Survey}

We used a one-stage self-weighting sampling design to select a representative random sample of households in the community. Between January and December 2012, every adult aged 18 
years or older and having slept at least two nights in the selected households during the previous seven nights were invited to participate in the study. Informed consent was obtained from all participants, interviews were conducted using standardized questionnaires, a genital examination was performed and bloods were collected at the study site. The following information was collected through standardized questionnaires: age, ethnic group, marriage history, occupation, education level, alcohol consumption, age at sexual debut, lifetime number of sexual partners, condom use at last sexual intercourse, HIV testing history (ever/never tested and date of the first HIV test) and, among women, pregnancy history. Among men, a genital examination was performed to determine male circumcision (MC) status. The date of circumcision was also collected.

\section{Laboratory procedure}

Each participant was invited to supply a venous blood sample. Samples were collected in plasma preparation tubes and centrifuged. A screening test for HIV (GenscreenTM HIV1/2 version 2, Bio-Rad, Marnes-la-Coquette, France) was performed on all plasma samples. For reactive samples, a confirmatory test was run (VironostikaTM, HIV Uni-Form II plus O, bioMérieux, Boxtel, Netherlands). If the sample reacted positively for both assays, a second confirmatory test was conducted (Murex HIV-1.2.O, Murex Biotech Ltd., Dartford, UK). Plasma samples testing positive for HIV were also tested for the presence of the most common antiretroviral drugs (ARV) currently in use in South Africa (Lamivudine, Stavudine, Zidovudine, Nevirapine, Efavirenz, Ritonavir, Lopinavir, Emtricitabine, Tenofovir, Abacavir, Atazanavir) using ultra performance liquid chromatography coupled with tandem mass spectrometry according to a slightly modified previously published method [17]. Plasma HIV1 RNA load was determined by reverse-transcription PCR using an assay designed to detect 
all M-group subtypes (Amplicor HIV-1 Monitor Test V1.5, Roche Diagnostic System Ins., Branchburg, New Jersey, USA) [18].

\section{Ethics}

Ethical clearance for the surveys was granted by the Human Research Ethics Committee (Medical) of the University of the Witwatersrand on May 8, 2007 (M070367).

\section{Outcomes}

Additionally to the HIV status of participants, our outcomes included the successive steps of the cascade of HIV care, defined as: i) having been ever tested for HIV; ii) testing positive for the use of any ARV; and iii) having viral suppression, defined as $\mathrm{VL}<400$ copies $/ \mathrm{mL}$ (alternative thresholds were also used: $<50$ or $<1000$ copies $/ \mathrm{mL}$ ). We also calculated the ratio of ARV-positive people over those HIV-negative. At the community-level, we calculated the detectable viral load proportion, defined as the proportion of untreated or treated but not virally suppressed HIV-infected people, and as such representing the fraction of the population potentially exposing their sexual partners to HIV $[13,19])$.

For participants testing positive for the use of ARVs, the ART profile was categorized as definite/probable/possible $1^{\text {st }}$-line regime, definite/probable/possible $2^{\text {nd }}$-line regime, or undetermined (see Table S1, Supplemental Digital Content 1, http://links.Iww.com/QAD/A932, which describes the ART profiles).

\section{Statistical analysis}

For each outcome, we calculate the percentage and 95\% Confidence Interval. For HIVpositivity and the different steps of the treatment cascade, we identified associated factors through univariate and multivariate Poisson regression, which allowed the calculation of 
unadjusted and adjusted Prevalence Rate Ratio (respectively, PRR and aPRR) [20]. Variables considered in the multivariate models included all covariates associated with the studied outcome with a p-value $<0.2$ in univariate analysis.

We conducted additional analyses restricted to the highly exposed age groups, defined as those age groups with a particularly high HIV incidence rate, including 18-29 year old women and 25-34 year old men [21]. The outcomes were also studied in the sub-population of women reporting having been pregnant during the past 12 months.

The number of participants testing positive for ARVs was expressed as a ratio relative to the number of HIV-negative participants in the sample (number non-directly dependent on ART programs). Using a basic model, (see Text, Supplemental Digital Content 2, http://links.Iww.com/QAD/A932, which describes the model), we estimated what this ratio would have been if every HIV-infected person in the community had received ART using the treatment threshold of CD4<200cells/ $\mu \mathrm{L}$ (which since 2005, has corresponded to the 2006 WHO guidelines [2]). This model assumed a stable population and a stable HIV epidemic (i.e. HIV incidence roughly equals AIDS-related mortality).

Analyses were performed using the statistical software R [23].

\section{Results}

\section{Sample characteristics}

A total of 3293 men and 3473 women participated in the study. The overall participation rate was $60 \%$. The mean age (median[Inter-Quartile Range]) was 31.8 years (27.0[22.0-38.6]) among men and 36.0 years (32.6[23.7-46.2]) among women. Background, behavioral and 
HIV testing characteristics of the population are presented in Table 1. Among 18-49 year old men (age group targeted for VMMC), the prevalence of MC was 46.2\%[95\% Confidence Interval: 44.3-48.0\%]. Among women, 12.9\%[11.8-14.0\%] reported having been pregnant during the past 12 months, among whom 93.8\%[91.1-96.0\%] reported having seen a health provider in relation to the pregnancy.

\section{HIV prevalence and factors associated with HIV-positivity}

HIV prevalence was $17.0 \%[15.7-18.3 \%]$ among men and 30.1\%[28.5-31.6\%] among women (overall: $23.7 \%[22.7-24.7 \%]$ ). Age-specific HIV prevalence is presented in Figure 1. Results of the risk factor analysis of HIV-positivity are presented in a table (see Table S2,

Supplemental Digital Content 3, http://links.Iww.com/QAD/A932, which describes the data).

\section{Uptake of HIV testing}

Overall, 59.1\%[57.4-60.8\%] of men and 79.5\%[78.2-80.9\%] of women reported having been previously tested for HIV. These proportions were 65.7\%[62.5-68.7\%] and 84.2\%[82.3$86.0 \%]$, respectively, among the highly-exposed age groups.

Among men, independent predictors of lifetime uptake of HIV testing were having ever been married, being at school, being HIV-positive and being circumcised (Table 2). This latter factor was the strongest predictor of having ever been tested. Among circumcised men, $23.7 \%[215 / 694,20.9-26.6 \%]$ of those having ever been tested reported the date of the first HIV test as being within a month of the date of the VMMC.

Among women, independent predictors of lifetime uptake of HIV testing were employment and having been pregnant during the past 12 months. Among women reporting having received prenatal care, 96.2\%[93.4-97.9\%] reported having been tested for HIV (it is not 
known whether they were tested as part of prenatal care), and 33.8\%[29.3-38.6\%] of those reported that they underwent their first HIV test within the past 12 months.

Among participants testing positive for HIV in this study, 33.9\%[29.9-38.0\%] of men and $13.2 \%[11.2-15.4 \%]$ of women reported having never been tested for HIV.

\section{ART coverage}

Among 558 men and 1041 women testing positive for HIV, 21.0\%[17.7-24.6\%] and $30.5 \%[27.7-33.3 \%]$, respectively, tested positive for one or more ARV (overall: $27.1 \%$ [25.029.4\%]). Among untreated HIV-positive participants, 39.0\%[34.4-43.7\%] of men and $16.5 \%[13.8-19.4 \%]$ of women reported having never been tested for HIV.

Factors associated with the use of ARVs among both genders were age and condom use during their last sexual encounter (Table 3). Additionally, being unemployed (vs. employed) among men, and having a low alcohol consumption among women, were independently associated with ARVs-positivity. MC status was not associated with ARVs-positivity, while among women from highly-exposed age groups, recent pregnancy was associated with ARVspositivity (aPRR=2.08[1.22-3.57]).

Among the 119 women testing positive for HIV and reporting having been pregnant during the past 12 months, 31.1\%[22.9-40.2\%] were using ARVs.

Among men testing positive for ARVs, 14.5\%[8.7-22.2\%] reported having never been tested for HIV. Among women, this figure was 5.7\%[3.4-8.8\%].

Among the 434 participants testing positive for any ARV, the majority were definitely (303; $69.8 \%)$, probably $(87 ; 20.0 \%)$ or possibly $(11 ; 2.5 \%)$ using first-line regimen ARVs; 16 $(3.7 \%), 8(1.8 \%)$ and $1(0.2 \%)$, respectively, were definitely, probably or possibly using second-line regimen ARVs, while the remaining 8 (1.8\%) presented an undetermined profile. 


\section{Viral Load distribution among people receiving ART}

Among the 432 participants testing positive for ARVs, 405 had an available VL measure. Among these, the proportion with viral load under the thresholds of $1000 \mathrm{copies} / \mathrm{mL}$, 400copies/mL and 50copies/mL were respectively 94.1\%[91.3-96.2\%]; 91.9\%[88.7-94.3\%] and $78.3 \%[73.9-82.2 \%]$. In univariate analysis, none of the studied risk factors were found to be significantly associated with VL suppression (see Table S3, Supplemental Digital Content 4, http://links.Iww.com/QAD/A932, which describes the results of the analysis). None of the participants with a count of VL>1000copies/mL was under a definite, probable or possible $2^{\text {nd }}$-line ART regime, and thus potentially in need of a $3^{\text {rd }}$-line regime.

\section{Overall cascade of HIV care and viral suppression}

Figure 2 summarizes the cascade of HIV care in Orange Farm. Overall, 23.7\%[21.6-25.9\%] of all HIV-infected people had a VL<400copies/mL. This proportion was significantly higher among women $(27.0 \%[24.3-29.9 \%])$ than among men (17.5\%[14.4-20.9\%], $\mathrm{p}<0.001)$; and was lower among the highly-exposed age groups: $15.6 \%[12.1-19.7 \%]$ among women and 8.4\%[5.0-13.1\%] among men (overall: $13.0 \%[10.4-16.1 \%]$ ). At the population level, the detectable viral load proportion was 17.8\%[16.9-18.7\%] (21.6\%[20.3-23.0\%] among women and $13.8 \%[12.6-15.0 \%]$ among men).

\section{Assessing the effectiveness of ART programs}

We calculated the ratio of people using ARVs to those HIV-negative to be 0.084 . Using the model described in Annex 1, we estimate that, if ART programs implemented in Orange Farm since 2005 were successful in averting every AIDS-related death, this ratio would be 0.184 . By comparing the observed ratio to that calculated under the hypothesis of maximum 
effectiveness, we estimate the effectiveness of the ART program in preventing AIDS-related deaths to be $46 \%$.

\section{Discussion}

\section{Main results}

In 2012, in a peri-urban South-African community hyper-endemic for HIV, $23.7 \%$ of all HIVinfected people were virally suppressed. Furthermore, this proportion was significantly lower among age groups most exposed to HIV infection. These levels can be considered as a starting point for developing strategic plans for reaching the proposed UNAIDS target for 2020, namely to achieve viral suppression among $73 \%$ of all people living with HIV. A large majority of the population reported having ever been tested for HIV, whereas just over one in four people living with HIV were receiving ART. When correctly taken, ART was highly effective in achieving viral suppression. Using a basic model, we also demonstrate that ART programs conducted until 2012 have had an effectiveness of 47 to $67 \%$ in preventing AIDSrelated deaths in this community.

\section{Limitations}

This study has several limitations. We defined steps along the cascade of HIV care that differ from those suggested in relation to the proposed UNAIDS target [9], with specific reference to the first two steps (percentage of lifetime HIV testing and proportion of those testing positive for the use of ARVs). We cannot infer the percentage of diagnosed HIV infections from information on lifetime uptake of HIV testing. However, the percentage of HIV-infected participants reported having never been tested for HIV may be interpreted as a lower boundry of the proportion of undiagnosed HIV infections. Furthermore, the proportion of HIV-infected participants testing positive for ARVs may underestimate the true proportion of participants 
having initiated ART, because participants receiving ART but not taking treatment at the time of the survey would test negative for ART. However, our third cascade indicator, the percentage of HIV-infected participants with suppressed VL, integrates information from previous steps and is comparable with that proposed by UNAIDS. Moreover, the results of this study do not rely on longitudinal data, and thus do not allow for a comprehensive understanding of the dynamics that may affect the different steps along the HIV cascade [24]. However, the cross-sectional nature of our data presents a snapshot of the cascade of care in Orange Farm that may be representative at the community level. Moreover, as we rely on data collected from a representative sample of the population, our indicator has the advantage of being less affected by reporting or participation bias than results obtained in clinical settings [13]. Other limitations were that a) we have used high incidence groups as a proxy for high transmitters and b) the questionnaire should have included questions about date of most recent HIV test, as well as date of the first test, and some indication of how many tests there were in between.

\section{HIV testing}

The proportions of the population having previously been tested for HIV in our study are very similar to those documented at the national level in South African [21]. In particular, almost all women having recently been pregnant reported having ever been tested for HIV, which may reflect the impact of prevention of mother-to-child transmission programs $[25,26]$. The level of lifetime HIV testing documented in South Africa is among the highest in sub-Saharan Africa [27]. However, in this study, at least $17 \%$ and $39 \%$ of HIV-infected women and men did not know their HIV status, which highlights the need to strengthen HIV testing programs. More specifically, repeat HIV testing should be promoted to allow earlier linkage to care and ART initiation [28]. Our data did not provide direct information on this issue, but results on 
lifetime testing suggest that the proportion of people who have been repeatedly tested is low, especially among men. Previous studies conducted in South Africa suggest that the proportion of repeat testers among HIV test users ranges from $26 \%$ to $71 \%$, depending on the local and testing context [29-31].

\section{ART coverage}

The proportion of HIV-infected people testing positive for the use of ARVs in our study was slightly lower than that estimated in a 2012 national population-based survey in South Africa (31.2\%), with the proportion being consistently higher among women than men [21]. In 2013, in a township in the Cape Town area, Kranzer et al reported that $33.5 \%$ of all HIV-infected individuals were receiving ART [32]. This slightly higher estimate may be explained by overestimation due to self-reporting. The proportion of people on second-line treatment regimes in our study was close to the WHO projections for low- and middle- income countries [33].

\section{Effect of VMMC campaigns}

The study was conducted in a community where VMMC has been intensively promoted as part of a combined HIV prevention package, including HIV counseling and testing (HCT), since 2008 [16]. We therefore observed a probable secondary benefit of VMMC programs: circumcised men were more likely to have ever been tested for HIV than uncircumcised men. Moreover, among circumcised men, nearly one in four reported having undergone a first HIV test as part of the VMMC procedure.

\section{Estimation of ART program effectiveness}

While significant progress has been made in scaling up the provision of ART to eligible people living with HIV in sub-Saharan Africa, coverage remains sub-optimal. For example, in 2009, ART coverage in South Africa, using the 2006 WHO guidelines (CD4<200cells $/ \mu$ L) was estimated at around 56\% [34]. National-level coverage was estimated by UNAIDS using 
a model which is based on national epidemiological data and assumptions on average survival rates with and without ART, and average time between sero-conversion and eligibility for treatment [35]. Using a basic model and relying on the same kind of data and assumptions, we estimated that the effectiveness of ART programs was less than $50 \%$ in preventing AIDSrelated deaths in the Orange Farm community between 2005 and 2012. These results highlight the need for better efficiency in every step of the cascade of HIV care, from HIV testing and diagnosis, to ART initiation, retention in care and adherence to treatment $[11,36]$.

\section{Level of viral suppression and impact on HIV incidence}

The level of viral suppression among the adult population infected with HIV in the Orange Farm community was found to be very similar to the 2013 UNAIDS estimate for Sub-Saharan Africa of $24 \%$ [12]. A rough estimate of the impact of such a level of viral suppression might be obtained by comparing the detectable viral load proportion, i.e. the fraction of the population potentially exposing partners to HIV $[13,19]$ to the crude HIV prevalence in the community. This basic calculation suggests a decrease in HIV incidence of $25 \%$ due to the preventive effect of ART. However, the true preventive effect of ART may have been lower, as lower levels of viral suppression were observed in the younger age groups among whom HIV incidence is at its highest levels. At the 2012 coverage level, we therefore cannot expect ART to have had a large impact on HIV incidence in this community.

\section{Optimistic results}

Our study shows that people receiving ART were more likely to report condom use at the last sexual encounter compared to untreated HIV-infected participants. This association may reflect the behavioral preventive effect of ART that has previously been described [37-40]. 
Another encouraging result from our study is that, when ARVs are correctly taken, and thus detectable in blood, their effectiveness in suppressing HIV viral load is high. Close to all treated participants presented a $\mathrm{VL}<1000$ copies $/ \mathrm{mL}$, which is the usual threshold of effective treatment. However, our results do not provide evidence to help understand why some patients interrupt or are insufficiently adherent to their treatment.

\section{Conclusions}

This study allowed the assessment of the gap between the 2012 level of viral suppression among the HIV-infected population of a hyper-endemic community in South Africa and the proposed UNAIDS treatment targets for 2020. The Orange Farm township is fairly representative of other semi-urban areas and our results may therefore be generalizable to those obtained in other sub-Saharan hyper-endemic semi-urban settings. While good progress has been made in the last decade in providing treatment to people living with HIV, the study shows that ART programs in 2012 were still suboptimal in delivering treatment to every person eligible for treatment according to the 2006 WHO treatment guidelines. Changing the HIV treatment eligibility criteria in itself will not be sufficient to reach the 2020 targets; there is an urgent need to improve the effectiveness of ART programs. Our results suggest that HIV testing and ART initiation, rather than ART effectiveness if actually taken, are crucial steps in need of improvement in order to achieve effective ART programs. 


\section{Acknowledgements}

We would like to thank the entire research team of Progressus Research and Development and specifically Agenda Gumbo for organizing the data entry of this study. We would like to thank Gaph Phatedi and Audrey Mkwanazi for support. We would like to thank the community of Orange Farm and specifically the Community Advisory Board of Orange Farm chaired by Portia Ntshangase.

\section{Source of funding}

We acknowledge support from the French Research Agency ANRS (Grant 12285).

\section{Competing interests}

The authors declare that they have no competing interests.

\section{Authors' contribution}

All authors have read and approved the manuscript. Substantial contributions to conception and design: BA, JB, RRT, DT and PL Preformed the acquisition of data: RRT, DT, JB and PL. Conducted the biological analysis of samples: EC, BS, AP, DAL and AP. Preformed the statistical analysis: KJ, BA. Interpretation of data: KJ, BA, GP, AP, PL, JB and EG. Wrote the first draft: KJ and BA. Contributed to writing the paper: AP, JB, EG, DAL and GP.

\section{Previous presentation}

Preliminary and partial results were presented at the 8th IAS Conference on HIV Pathogenesis, Treatment \& Prevention 19-22 July 2015, Vancouver, Canada (Abstract MOAC0102) and published as abstract in J Int AIDS Soc. 2015; 18(5Suppl 4): 20479. 


\section{References}

1 Connor EM, Sperling RS, Gelber R, Kiselev P, Scott G, O’Sullivan MJ, et al. Reduction of maternal-infant transmission of human immunodeficiency virus type 1 with zidovudine treatment. Pediatric AIDS Clinical Trials Group Protocol 076 Study Group. N Engl J Med 1994; 331:1173-1180.

2 WHO. Antiretroviral therapy for HIV infection in adults and adolescents.

Recommendations for a public health approach: 2006 revision. Geneva, Switzerland: ; 2006. http://www.who.int/hiv/pub/guidelines/artadultguidelines.pdf.

3 Cohen MS, Chen YQ, McCauley M, Gamble T, Hosseinipour MC, Kumarasamy N, et al. Prevention of HIV-1 infection with early antiretroviral therapy. N Engl J Med 2011; 365:493-505.

4 Tanser F, Bärnighausen T, Grapsa E, Zaidi J, Newell M-L. High coverage of ART associated with decline in risk of HIV acquisition in rural KwaZulu-Natal, South Africa. Science 2013; 339:966-971.

5 Baggaley RF, White RG, Hollingsworth TD, Boily M-C. Heterosexual HIV-1 infectiousness and antiretroviral use: systematic review of prospective studies of discordant couples. Epidemiol Camb Mass 2013; 24:110-121.

6 WHO. Consolidated guidelines on the use of antiretroviral drugs for treating and preventing HIV infection. Recommandations for a Public Health approach. Geneva, Switzerland: ; 2013.

7 Eaton JW, Johnson LF, Salomon JA, Bärnighausen T, Bendavid E, Bershteyn A, et al. HIV treatment as prevention: systematic comparison of mathematical models of the potential impact of antiretroviral therapy on HIV incidence in South Africa. PLoS Med 2012; 9:e1001245. 
8 Hontelez JAC, Lurie MN, Bärnighausen T, Bakker R, Baltussen R, Tanser F, et al. Elimination of HIV in South Africa through Expanded Access to Antiretroviral Therapy: A Model Comparison Study. PLoS Med 2013; 10:e1001534.

9 UNAIDS. 90-90-90: An ambitious treatment target to help end the AIDS epidemic. Geneva, Switzerland: UNAIDS; 2014.

10 Rosen S, Fox MP. Retention in HIV Care between Testing and Treatment in Sub-Saharan Africa: A Systematic Review. PLoS Med 2011; 8:e1001056.

11 Kranzer K, Govindasamy D, Ford N, Johnston V, Lawn SD. Quantifying and addressing losses along the continuum of care for people living with HIV infection in sub-Saharan Africa: a systematic review. J Int AIDS Soc 2012; 15:17383.

12 Global Report: UNAIDS report on the global AIDS epidemic 2013. Geneva: UNAIDS; 2013.

13 Miller WC, Powers KA, Smith MK, Cohen MS. Community viral load as a measure for assessment of HIV treatment as prevention. Lancet Infect Dis 2013; 13:459-464.

14 The National Antenatal Sentinel HIV and Syphilis Prevalence Survey in South Africa. South Africa: National Department of Health; 2010.

15 Auvert B, Taljaard D, Lagarde E, Sobngwi-Tambekou J, Sitta R, Puren A. Randomized, controlled intervention trial of male circumcision for reduction of HIV infection risk: the ANRS 1265 Trial. PLoS Med 2005; 2:e298.

16 Auvert B, Taljaard D, Rech D, Lissouba P, Singh B, Bouscaillou J, et al. Association of the ANRS-12126 male circumcision project with HIV levels among men in a South African township: evaluation of effectiveness using cross-sectional surveys. PLoS Med 2013; 10:e1001509.

17 Jung BH, Rezk NL, Bridges AS, Corbett AH, Kashuba AD. Simultaneous determination of 17 antiretroviral drugs in human plasma for quantitative analysis with liquid 
chromatography-tandem mass spectrometry. Biomed Chromatogr 2007; 21:1095-104.

18 Triques K, Coste J, Perret JL, Segarra C, Mpoudi E, Reynes J, et al. Efficiencies of four versions of the AMPLICOR HIV-1 MONITOR test for quantification of different subtypes of human immunodeficiency virus type 1. J Clin Microbiol 1999; 37:110-116.

19 Kelley CF, Rosenberg ES, O’Hara BM, Frew PM, Sanchez T, Peterson JL, et al. Measuring population transmission risk for HIV: an alternative metric of exposure risk in men who have sex with men (MSM) in the US. PloS One 2012; 7:e53284.

20 Barros AJD, Hirakata VN. Alternatives for logistic regression in cross-sectional studies: an empirical comparison of models that directly estimate the prevalence ratio. BMC Med Res Methodol 2003; 3:21.

21 Shisana O, Rehle T, Simbayi LC, Zuma K, Jooste S, Zungu N, et al. South African National HIV Prevalence, Incidence and Behaviour Survey, 2012. Captown, South Africa: HSRC Press; 2014.

22 Rehle TM, Hallett TB, Shisana O, Pillay-van Wyk V, Zuma K, Carrara H, et al. A Decline in New HIV Infections in South Africa: Estimating HIV Incidence from Three National HIV Surveys in 2002, 2005 and 2008. PLoS ONE 2010; 5:e11094.

23 R Development Core Team. $R$ : a language and environment for statistical computing. $\mathrm{R}$ Foundation for Statistical Computing. Vienna, Austria: ; 2005.

24 Hallett TB, Eaton JW. A Side Door Into Care Cascade for HIV-Infected Patients? JAIDS J Acquir Immune Defic Syndr 2013; 63 Suppl 2:S228-232.

25 Barron P, Pillay Y, Doherty T, Sherman G, Jackson D, Bhardwaj S, et al. Eliminating mother-to-child HIV transmission in South Africa. Bull World Health Organ 2013; 91:70-74.

26 Goga AE, Dinh T-H, Jackson DJ, Lombard C, Delaney KP, Puren A, et al. First population-level effectiveness evaluation of a national programme to prevent HIV 
transmission from mother to child, South Africa. J Epidemiol Community Health

Published Online First: 4 November 2014. doi:10.1136/jech-2014-204535

27 Staveteig S, Wang S, Head SK, Bradley SEK, Nybro E. Demographic Patterns of HIV Testing Uptake in Sub-Saharan Africa - DHS Comparative Reports No. 30. ICF Macro; 2013.

28 Gras L, van Sighem A, Bezemer D, Smit C, Wit F, de Wolf F, et al. Lower mortality and earlier start of combination antiretroviral therapy in patients tested repeatedly for HIV than in those with a positive first test. AIDS Lond Engl 2011; 25:813-818.

29 Kranzer K, van Schaik N, Karmue U, Middelkoop K, Sebastian E, Lawn SD, et al. High prevalence of self-reported undiagnosed HIV despite high coverage of HIV testing: a cross-sectional population based sero-survey in South Africa. PloS One 2011; 6:e25244.

30 Regan S, Losina E, Chetty S, Giddy J, Walensky RP, Ross D, et al. Factors associated with self-reported repeat HIV testing after a negative result in Durban, South Africa. PloS One 2013; 8:e62362.

31 Tabana H, Doherty T, Rubenson B, Jackson D, Ekström AM, Thorson A. “Testing Together Challenges the Relationship": Consequences of HIV Testing as a Couple in a High HIV Prevalence Setting in Rural South Africa. PLoS ONE 2013; 8:e66390.

32 Kranzer K, Lawn SD, Johnson LF, Bekker L-G, Wood R. Community viral load and CD4 count distribution among people living with HIV in a South African Township: implications for treatment as prevention. J Acquir Immune Defic Syndr 1999 2013; 63:498-505.

33 Renaud-Théry F, Avila-Figueroa C, Stover J, Thierry S, Vitoria M, Habiyambere V, et al. Utilization patterns and projected demand of antiretroviral drugs in low- and middleincome countries. AIDS Res Treat 2011; 2011:749041.

34 WHO. Toward universal access: Scaling up priority HIV/AIDS intervention in health 
sector. Progress report 2010. Geneva: ; 2010.

35 Stover J, Johnson P, Zaba B, Zwahlen M, Dabis F, Ekpini RE. The Spectrum projection package: improvements in estimating mortality, ART needs, PMTCT impact and uncertainty bounds. Sex Transm Infect 2008; 84 Suppl 1:i24-i30.

36 Fox MP, Rosen S. Patient retention in antiretroviral therapy programs up to three years on treatment in sub-Saharan Africa, 2007-2009: systematic review. Trop Med Int Health TM IH 2010; 15 Suppl 1:1-15.

37 Kennedy C, O’Reilly K, Medley A, Sweat M. The impact of HIV treatment on risk behaviour in developing countries: a systematic review. AIDS Care 2007; 19:707-720.

38 Kaye DK, Kakaire O, Osinde MO, Lule JC, Kakande N. The impact of highly active antiretroviral therapy on high-risk behaviour of HIV-infected patients in sub-Saharan Africa. J Infect Dev Ctries 2013; 7:436-447.

39 Berhan A, Berhan Y. Is the Sexual Behaviour of HIV Patients on Antiretroviral therapy safe or risky in Sub-Saharan Africa? Meta-Analysis and Meta-Regression. AIDS Res Ther 2012; 9:14.

40 Jean K, Gabillard D, Moh R, Danel C, Desgrées-du-Loû A, N'takpe J-B, et al. Decrease in sexual risk behaviours after early initiation of antiretroviral therapy: a 24-month prospective study in Côte d'Ivoire. J Int AIDS Soc 2014; 17:18977. 
Table 1. Background, behavioral and HIV testing characteristics of the study population in Orange Farm, 2012.

\begin{tabular}{|c|c|c|}
\hline & $\begin{array}{l}\operatorname{Men}(\mathrm{N}=3293) \\
\% *\end{array}$ & $\begin{array}{l}\text { Women }(\mathrm{N}=3473) \\
\% *\end{array}$ \\
\hline \multicolumn{3}{|l|}{ Age } \\
\hline $18-24$ & $41.5 \%(1367 / 3293)$ & $30.3 \%(1053 / 3473)$ \\
\hline $25-29$ & $18.4 \%(606 / 3293)$ & $13.8 \%(481 / 3473)$ \\
\hline $30-34$ & $9.9 \%(326 / 3293)$ & $10.7 \%(373 / 3473)$ \\
\hline $35-39$ & $7.3 \%(239 / 3293)$ & $10.0 \%(348 / 3473)$ \\
\hline$>=40$ & $22.9 \%(755 / 3293)$ & $35.1 \%(1218 / 3473)$ \\
\hline \multicolumn{3}{|l|}{ Ethnic group } \\
\hline Sotho & $34.0 \%(1120 / 3292)$ & $37.3 \%(1295 / 3472)$ \\
\hline ulu & $41.0 \%(1349 / 3292)$ & $37.6 \%(1306 / 3472)$ \\
\hline Other & $25.0 \%(823 / 3292)$ & $25.1 \%(871 / 3472)$ \\
\hline \multicolumn{3}{|l|}{ Occupation } \\
\hline Employed & $44.7 \%(1471 / 3291)$ & $26.7 \%(926 / 3473)$ \\
\hline Unemployed & $34.9 \%(1149 / 3291)$ & $55.5 \%(1926 / 3473)$ \\
\hline Other & $20.4 \%(671 / 3291)$ & $17.9 \%(621 / 3473)$ \\
\hline \multicolumn{3}{|l|}{ Marriage history } \\
\hline Never married & $55.6 \%(1831 / 3293)$ & $40.4 \%(1404 / 3473)$ \\
\hline Ever married & $44.4 \%(1462 / 3293)$ & $59.6 \%(2069 / 3473)$ \\
\hline \multicolumn{3}{|l|}{ Education level } \\
\hline$<$ Level 12 and not at school & $56.1 \%(1847 / 3293)$ & $64.0 \%(2221 / 3469)$ \\
\hline Level 12 completed & $11.8 \%(387 / 3293)$ & $7.6 \%(263 / 3469)$ \\
\hline At school (<leve1 2) & $32.2 \%(1059 / 3293)$ & $28.4 \%(985 / 3469)$ \\
\hline \multicolumn{3}{|l|}{ Alcohol consumption } \\
\hline$<1$ per week & $67.5 \%(2224 / 3293)$ & $90.8 \%(3150 / 3471)$ \\
\hline$>=1$ per week & $32.5 \%(1069 / 3293)$ & $9.2 \%(321 / 3471)$ \\
\hline
\end{tabular}

Copyright @ 2016 Wolters Kluwer Health, Inc. Unauthorized reproduction of this article is prohibited. 


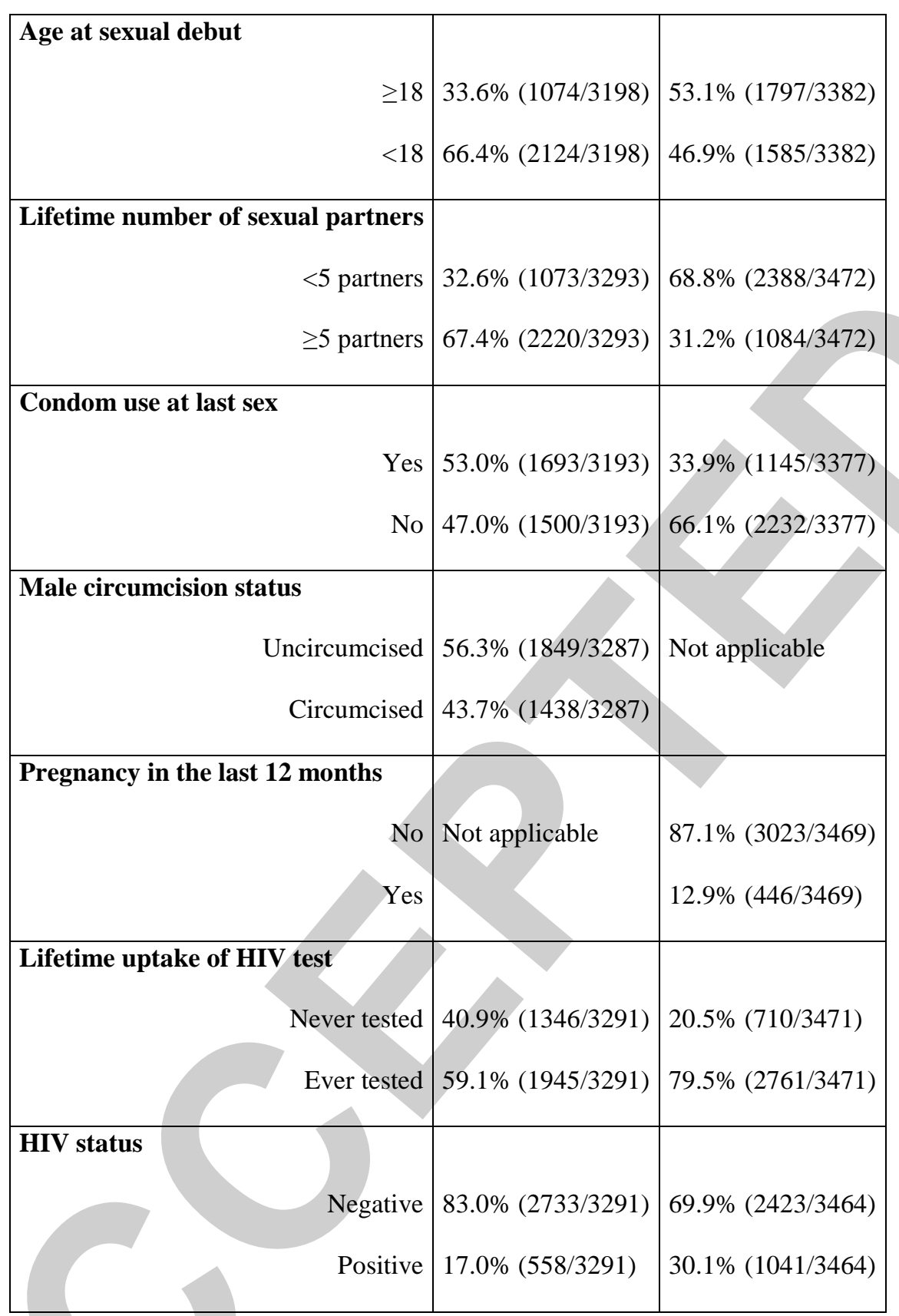

*Percentage are expressed as proportion of non-missing values.

Copyright $\odot 2016$ Wolters Kluwer Health, Inc. Unauthorized reproduction of this article is prohibited. 
Table 2. Factor associated with lifetime uptake of HIV testing among men and women in Orange Farm, 2012.

\begin{tabular}{|c|c|c|c|c|c|c|}
\hline & \multicolumn{3}{|c|}{$\operatorname{Men}(\mathrm{N}=3291)$} & \multicolumn{3}{|c|}{ Women $(\mathrm{N}=3471)$} \\
\hline & $\begin{array}{l}\text { \% ever tested } \\
\text { (n) }\end{array}$ & PRR $[95 \% I C]$ & aPRR[95\% IC] & $\begin{array}{l}\text { \% ever tested } \\
\text { (n) }\end{array}$ & PRR[95\% IC] & $\operatorname{aPRR}[95 \% \mathrm{IC}]$ \\
\hline \multicolumn{7}{|l|}{ Age } \\
\hline $18-24$ & $52.6 \%(1366)$ & 1 & 1 & $81.2 \%(1052)$ & 1 & 1 \\
\hline $25-29$ & $64.2 \%(606)$ & $1.22[1.08-1.38]$ & $1.13[0.99-1.30]$ & $95.6 \%(481)$ & $1.18[1.05-1.32]$ & $1.09[0.97-1.23]$ \\
\hline $30-34$ & $68.4 \%(326)$ & $1.30[1.12-1.51]$ & $1.21[1.02-1.43]$ & $92.8 \%(373)$ & 1.14[1.01-1.29] & $1.06[0.92-1.21]$ \\
\hline $35-39$ & $61.5 \%$ (239) & $1.17[0.98-1.39]$ & $1.06[0.86-1.30]$ & $90.8 \%(347)$ & $1.12[0.98-1.27]$ & $1.04[0.90-1.20]$ \\
\hline$\geq 40$ & $61.9 \%(754)$ & $1.18[1.05-1.32]$ & $1.13[0.96-1.32]$ & $64.5 \%(1218)$ & $0.79[0.72-0.88]$ & $0.79[0.70-0.89]$ \\
\hline \multicolumn{7}{|l|}{ Ethnic group } \\
\hline Sotho & $57.0 \%(1119)$ & 1 & Not entered & $78.3 \%$ (1295) & & Not entered \\
\hline Zulu & $60.0 \%(1349)$ & $1.05[0.95-1.17]$ & & $82.8 \%$ (1305) & $1.06[0.97-1.15]$ & \\
\hline Other & $60.5 \%(822)$ & $1.06[0.94-1.19]$ & & $76.6 \%(870)$ & $0.98[0.89-1.08]$ & \\
\hline \multicolumn{7}{|l|}{ Occupation } \\
\hline Employed & $61.5 \%(1470)$ & 1 & 1 & $83.5 \%(926)$ & 1 & 1 \\
\hline Unemployed & $59.7 \%(1148)$ & $0.97[0.88-1.07]$ & $1.02[0.92-1.12]$ & $82.5 \%$ (1924) & $0.99[0.91-1.08]$ & $0.94[0.86-1.03]$ \\
\hline Other & $52.8 \%(671)$ & $0.86[0.76-0.97]$ & $0.98[0.83-1.14]$ & $64.6 \%(621)$ & $0.77[0.69-0.87]$ & $0.76[0.66-0.88]$ \\
\hline
\end{tabular}

Copyright @ 2016 Wolters Kluwer Health, Inc. Unauthorized reproduction of this article is prohibited. 


\begin{tabular}{|c|c|c|c|c|c|c|}
\hline \multicolumn{7}{|l|}{ Marriage history } \\
\hline Never married & $54.3 \%(1830)$ & 1 & 1 & $81.3 \%(1403)$ & 1 & Not entered \\
\hline Ever married & $65.1 \%(1461)$ & $1.20[1.10-1.31]$ & $1.18[1.05-1.32]$ & $78.4 \%(2068)$ & $0.96[0.89-1.04]$ & \\
\hline \multicolumn{7}{|l|}{ Education level } \\
\hline$<$ Level 12 and not at school & $56.9 \%(1845)$ & 1 & 1 & $76.3 \%(2219)$ & & 1 \\
\hline Level 12 completed & $47.3 \%(387)$ & $0.83[0.71-0.97]$ & $0.99[0.80-1.23]$ & $74.1 \%(263)$ & $0.97[0.84-1.12]$ & $1.18[0.98-1.42]$ \\
\hline At school (<leve1 2) & $67.3 \%(1059)$ & $1.18[1.08-1.30]$ & $1.21[1.09-1.34]$ & $88.2 \%(985)$ & $1.16[1.07-1.25]$ & $1.09[0.99-1.19]$ \\
\hline \multicolumn{7}{|l|}{ Alcohol consumption } \\
\hline$<1$ per week & $59.8 \%(2223)$ & 1 & $\mathrm{No}$ & $79.4 \%(3149)$ & 1 & Not entered \\
\hline$\geq 1$ per week & $57.7 \%(1068)$ & $0.96[0.88-1$ & & $80.6 \%(320)$ & $1.02[0.89-1.15]$ & \\
\hline \multicolumn{7}{|l|}{ Age at sexual debut } \\
\hline$\geq 18$ & $60.8 \%(1073)$ & 1 & Not entered & $78.1 \%(1797)$ & 1 & 1 \\
\hline$<18$ & $59.0 \%(2123)$ & $0.97[0.88-1.07]$ & & $83.4 \%(1583)$ & $1.07[0.99-1.15]$ & $1.05[0.97-1.13]$ \\
\hline \multicolumn{7}{|l|}{ Lifetime number of sexual partners } \\
\hline$<5$ partners & $54.5 \%(1072)$ & 1 & 1 & $77.4 \%(2386)$ & 1 & 1 \\
\hline$\geq 5$ partners & $61.3 \%(2219)$ & $1.13[1.02-1.24]$ & $1.05[0.95-1.16]$ & $84.3 \%(1084)$ & $1.09[1.01-1.18]$ & $1.05[0.97-1.14]$ \\
\hline \multicolumn{7}{|l|}{ Condom use at last sex } \\
\hline Yes & $59.3 \%(1693)$ & 1 & Not entered & $84.8 \%(1145)$ & 1 & 1 \\
\hline No & $60.1 \%(1498)$ & $1.01[0.93-1.11]$ & & $78.4 \%(2230)$ & $0.92[0.85-1.00]$ & $0.99[0.91-1.07]$ \\
\hline
\end{tabular}

Copyright $\odot 2016$ Wolters Kluwer Health, Inc. Unauthorized reproduction of this article is prohibited. 


\begin{tabular}{|c|c|c|c|c|c|c|}
\hline \multicolumn{7}{|l|}{ Male circumcision status } \\
\hline $\begin{array}{r}\text { Uncircumcised } \\
\text { Circumcised }\end{array}$ & $\begin{array}{l}53.6 \%(1849) \\
66.2 \%(1437)\end{array}$ & $\begin{array}{l}1 \\
1.23[1.13-1.35]\end{array}$ & $\begin{array}{l}1 \\
1.29[1.18-1.42]\end{array}$ & Not applicable & Not applicable & Not applicable \\
\hline \multicolumn{7}{|l|}{ Pregnancy in the last 12 months } \\
\hline $\begin{array}{l}\text { No } \\
\text { Yes }\end{array}$ & Not applicable & Not applicable & Not applicable & $\begin{array}{l}77.2 \%(3021) \\
95.7 \%(446)\end{array}$ & $\begin{array}{l}1 \\
1.23[1.12-1.37]\end{array}$ & $\begin{array}{l}1 \\
1.11[1.00-1.23]\end{array}$ \\
\hline \multicolumn{7}{|l|}{ HIV status } \\
\hline Negative & $57.6 \%(2731)$ & 1 & 1 & $76.4 \%(2422)$ & 1 & 1 \\
\hline Positive & $66.1 \%(558)$ & $1.15[1.02-1.28]$ & $1.14[1.01-1.29]$ & $86.8 \%(1040)$ & $1.14[1.05-1.23]$ & $1.06[0.97-1.15]$ \\
\hline
\end{tabular}

PRR: unadjusted Prevalence Rate Ratio. 95\%CI: 95\% Confidence Interval. aPRR: adjusted Prevalence Rate Ratio.

PRR and aPRR were computed from univariate and multivariate Poisson regression. The multivariate models included all covariate associated with the outcome with a p-value $<0.2$ in univariate analysis. 
Table 3. Factor associated with positivity to ARV among HIV-infected men and women in Orange Farm, 2012.

\begin{tabular}{|c|c|c|c|c|c|c|}
\hline & \multicolumn{3}{|c|}{ Men $(\mathrm{N}=558)$} & \multicolumn{3}{|c|}{ Women $(\mathrm{N}=1041)$} \\
\hline & $\begin{array}{l}\% \text { positive } \\
\text { to ART (n) }\end{array}$ & PRR[95\% IC] & aPRR $[95 \%$ IC $]$ & $\begin{array}{l}\% \text { positive } \\
\text { to ART (n) }\end{array}$ & PRR[95\%IC] & aPRR[95\% IC] \\
\hline \multicolumn{7}{|l|}{ Age } \\
\hline $18-24$ & $7.0 \%(71)$ & 1 & & $13.1 \%(183)$ & 1 & 1 \\
\hline $25-29$ & $8.4 \%$ & $1.19[0.41-3.89]$ & $2.35[0.67-10.94]$ & $22.9 \%(192)$ & $1.75[1.07-2.92]$ & $1.63[0.99-2.74]$ \\
\hline $30-34$ & $11.5 \%(96)$ & $1.63[0.59-5.16]$ & $3.71[1.09-17.17]$ & $30.9 \%(188)$ & $2.35[1.48-3.85]$ & $2.07[1.28-3.45]$ \\
\hline $35-39$ & $24.0 \%(104)$ & $3.41[1.42-10.11]$ & $6.87[2.23-30.29]$ & $37.1 \%(167)$ & $2.83[1.79-4.62]$ & $2.39[1.48-3.99]$ \\
\hline$\geq 40$ & $37.2 \%(180)$ & $5.29[2.36-15.09]$ & 9.52[3.19-41.32] & $41.5 \%(311)$ & $3.16[2.09-5.01]$ & $2.77[1.77-4.53]$ \\
\hline \multicolumn{7}{|l|}{ Ethnic group } \\
\hline Sotho & $24.2 \%(190)$ & 1 & & $31.2 \%(384)$ & 1 & \\
\hline Zulu & $17.2 \%(227)$ & $0.71[0.46-1.09]$ & Not entered & $28.0 \%(400)$ & $0.90[0.69-1.16]$ & Not entered \\
\hline Other & $22.7 \%(141)$ & $0.94[0.59-1.47]$ & & $33.2 \%(256)$ & $1.06[0.80-1.40]$ & \\
\hline \multicolumn{7}{|l|}{ Occupation } \\
\hline Employed & $17.3 \%(318)$ & 1 & 1 & $33.4 \%(296)$ & 1 & \\
\hline Unemployed & $26.4 \%(193)$ & $1.53[1.04-2.24]$ & $1.54[1.04-2.27]$ & $30.0 \%(641)$ & $0.90[0.70-1.15]$ & Not entered \\
\hline Other & $23.4 \%$ & $1.35[0.67-2.48]$ & $1.23[0.55-2.44]$ & $25.0 \%(104)$ & $0.75[0.48-1.13]$ & \\
\hline
\end{tabular}

Copyright $\odot 2016$ Wolters Kluwer Health, Inc. Unauthorized reproduction of this article is prohibited. 


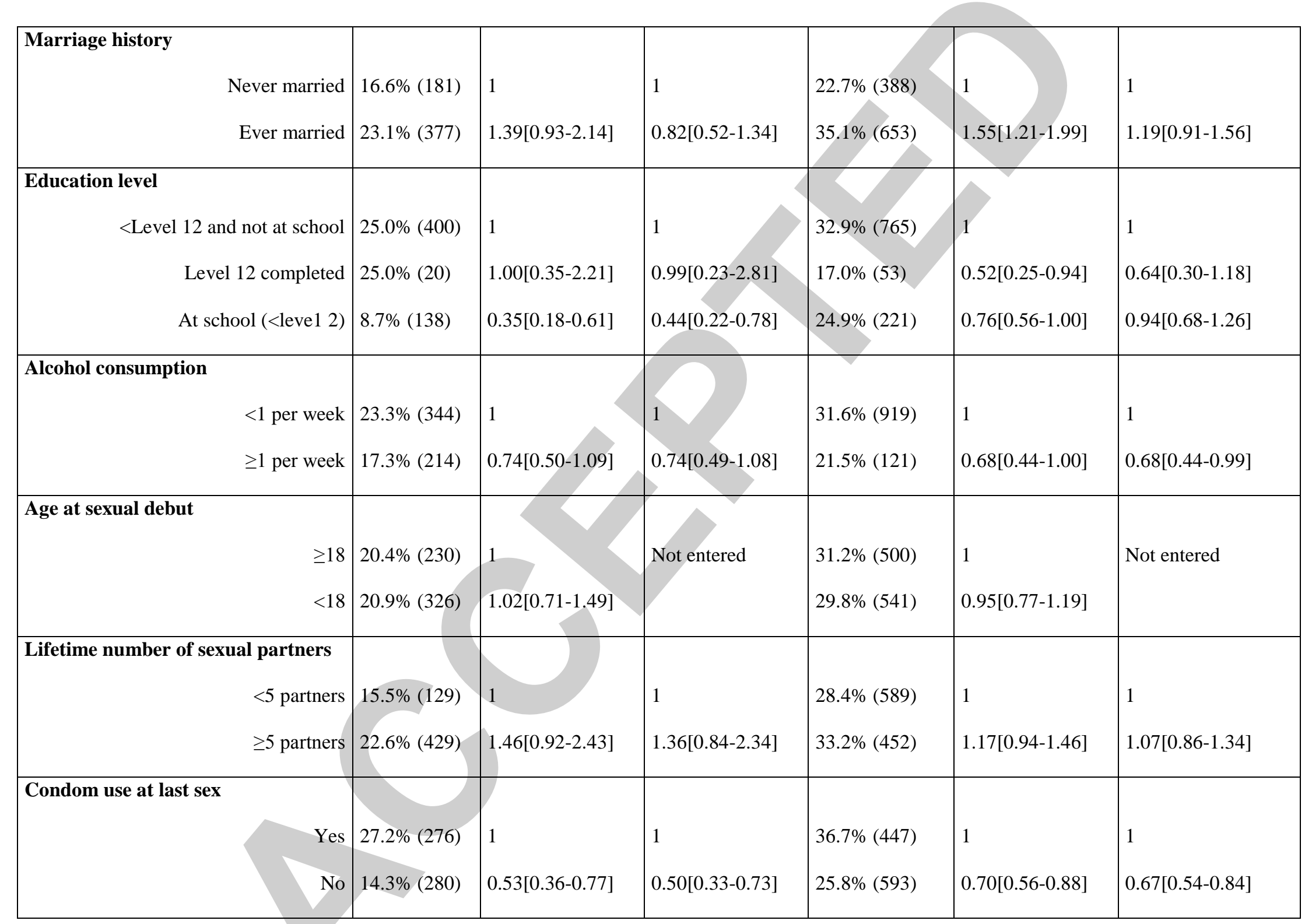

Copyright $\odot 2016$ Wolters Kluwer Health, Inc. Unauthorized reproduction of this article is prohibited. 


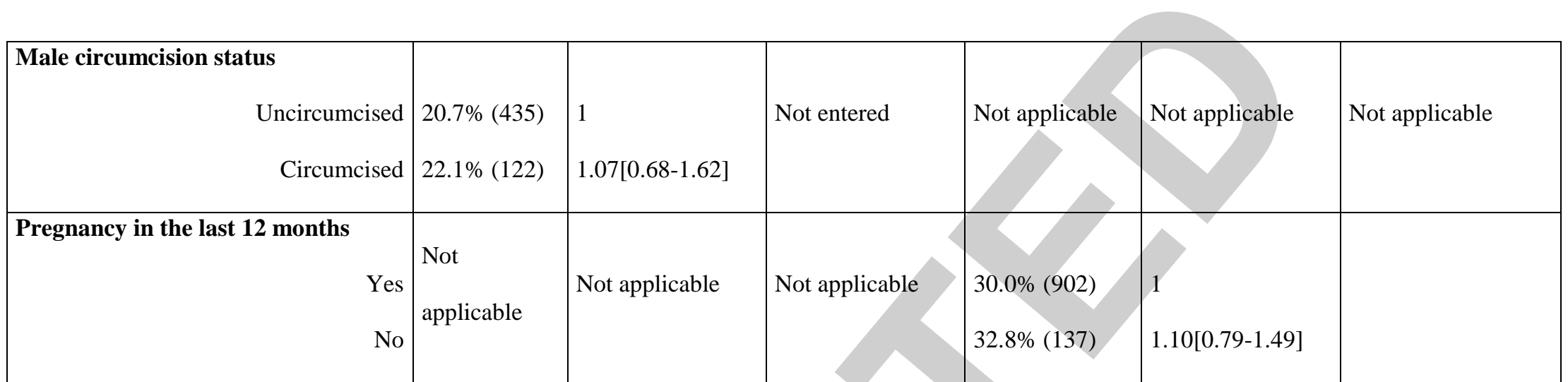

ARV: Antiretroviral drugs. PRR: unadjusted Prevalence Rate Ratio. 95\%CI: 95\% Confidence Interval. aPRR: adjusted Prevalence Rate Ratio. PRR and aPRR were computed from univariate and multivariate Poisson regression. The multivariate models included all covariate associated with the outcome with a p-value $<0.2$ in univariate analysis. 
Figure legend

Fig. 1: HIV prevalence across age groups among men and women in Orange Farm, 2012.

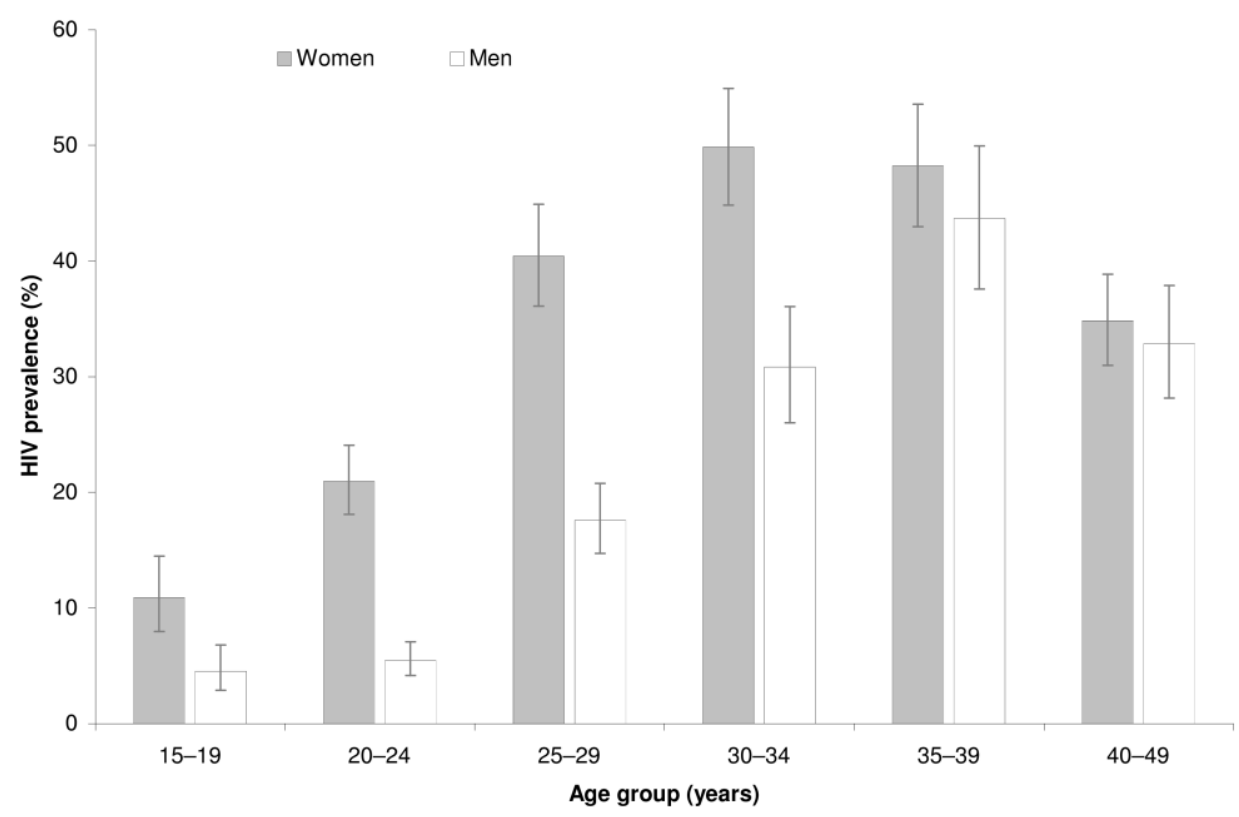

Copyright @ 2016 Wolters Kluwer Health, Inc. Unauthorized reproduction of this article is prohibited. 
Fig. 2. Percentage of ART-positivity and suppressed VL in Orange Farm, 2012.

The dolt bold line indicates the UNAIDS 2020 targets[9].

ART: Antiretroviral treatment; VL: Viral Load. Suppression threshold: VL $<400$ copies/mL. Highly exposed age group: 25-34y among men; 18-29y among women.

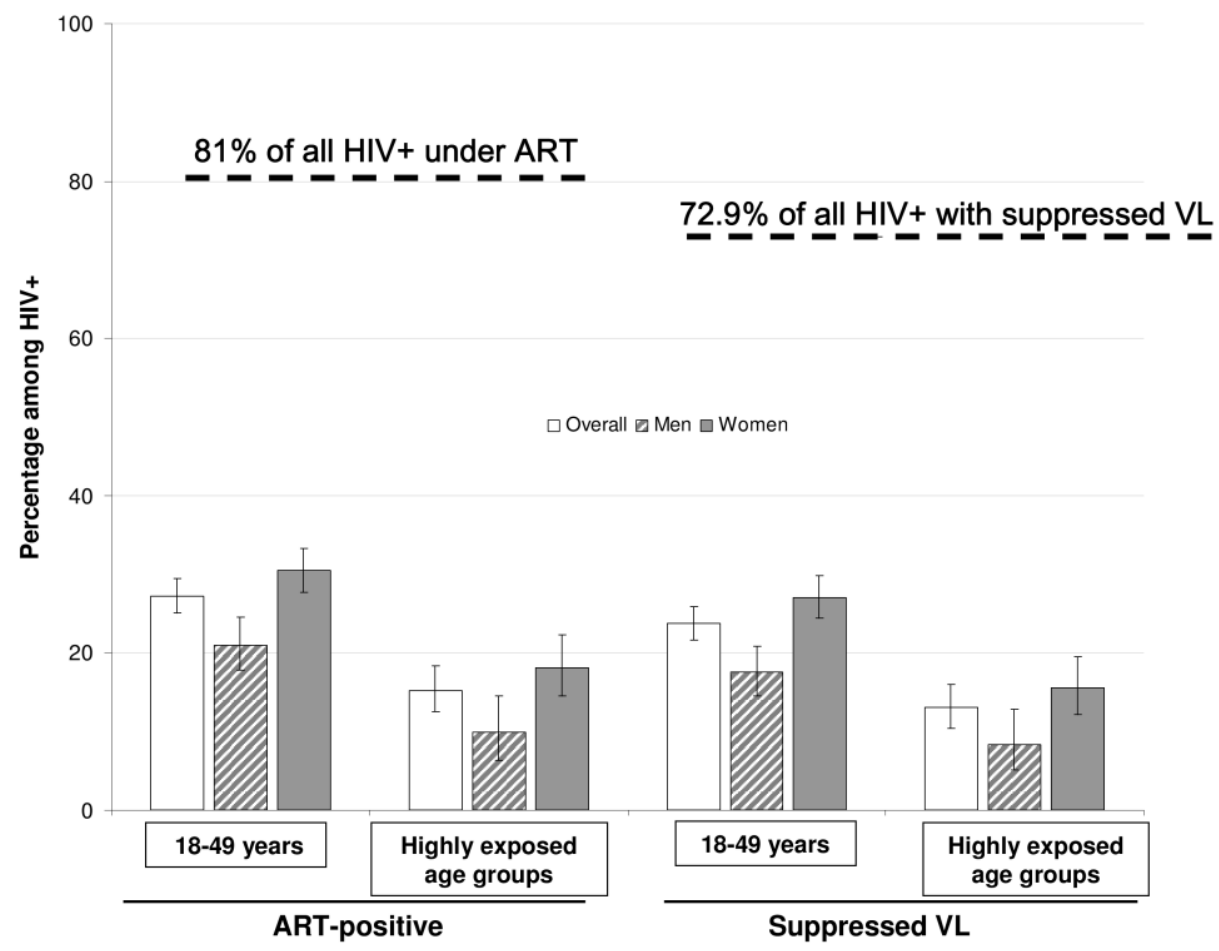

